\title{
Ion Pair First and Second Acidities of some $\beta$-Diketones and Aggregation of their Lithium and Cesium Enediolates in THF
}

\author{
Antonio Facchetti and Andrew Streitwieser \\ Contribution from Department of Chemistry, University of California, Berkeley, CA, 94720-1460
}

\section{Supporting Information}

\section{Contents}

Figure S1. UV-vis Spectra of $\mathbf{1}$ and of the Corresponding Lithium and Cesium Mono- and Di- Enolates in THF.

Figure S2. UV-vis spectra of 2 and its lithium and cesium mono- and di- enolates in THF. p. S4

Figure S3. UV-vis spectra of $\mathbf{3}$ and its lithium and cesium mono- and di- enolates in THF. p. S5

Figure S4. Absorbance of 1 for $1 \mathrm{~cm}$ pathlength at $324 \mathrm{~nm}$ p. S6

Figure S5. Absorbance of 1-Li for $1 \mathrm{~cm}$ pathlength at $\lambda_{\max }(340-342 \mathrm{~nm}) . \quad$ p. S6

Figure S6. Absorbance of $1-\mathrm{Li}_{2}$ for $1 \mathrm{~cm}$ pathlength at $\lambda_{\max }(379-381 \mathrm{~nm}) . \quad$ p. S7

Figure S7. Absorbance of 1-Cs for $1 \mathrm{~cm}$ pathlength at $\lambda_{\max }(418-421 \mathrm{~nm}) . \quad$ p. S7

Figure S8. Absorbance of $1-\mathrm{Cs}_{2}$ for $1 \mathrm{~cm}$ pathlength at $\lambda_{\max }(418-421 \mathrm{~nm}) . \quad$ p. S8

Figure S9. Absorbance of 2 for $1 \mathrm{~cm}$ pathlength at $312 \mathrm{~nm}$ p. S8

Figure S10. Absorbance of 2-Li for $1 \mathrm{~cm}$ pathlength at $\lambda_{\max }(333 \mathrm{~nm}) . \quad$ p. S9

Figure S11. Absorbance of 2- $\mathrm{Li}_{2}$ for $1 \mathrm{~cm}$ pathlength at $\lambda_{\max }(400-402 \mathrm{~nm}) . \quad$ p. S9

Figure S12. Absorbance of 2-Cs for $1 \mathrm{~cm}$ pathlength at $\lambda_{\max }(338-340 \mathrm{~nm}) . \quad$ p. S10

Dienediolates SI v. 2.1 
Figure S13. Absorbance of 2-Cs2 for $1 \mathrm{~cm}$ pathlength at $\lambda_{\max }(430-438 \mathrm{~nm}) . \quad$ p. S10

Figure S14. Absorbance of 3-Li for $1 \mathrm{~cm}$ pathlength at $\lambda_{\max }(329 \mathrm{~nm}) . \quad$ p. S11

Figure S15. Absorbance of 3- $\mathrm{Li}_{2}$ for $1 \mathrm{~cm}$ pathlength at $\lambda_{\max }(337 \mathrm{~nm})$ p. S11

Figure S16. Absorbance of 3-Cs for $1 \mathrm{~cm}$ pathlength at $\lambda_{\max }(336 \mathrm{~nm}) . \quad$ p. S12

Figure S17. Plots of K(obs) vs \{Enolate $\} / \mathrm{K}(\mathrm{obs})$ for 1-Li and 2-Li. p. S13

Figure S18. Plots of K(obs) vs \{Enolate $\} / \mathrm{K}(\mathrm{obs})$ for 3-Li, 1-Cs and 2-Cs. p. S14

Table S1. Properties of regression lines in Figure S17 and S18. p. S14

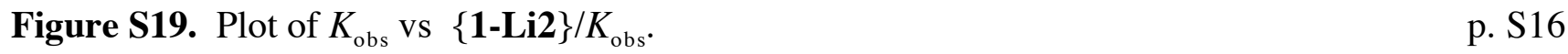

$\begin{array}{lr}\text { Figure S20. Plot of } K_{\mathrm{obs}} \text { Vs }\{\mathbf{2}-\mathbf{L i} 2\} / K_{\mathrm{obs}} & \text { p. S17 }\end{array}$

Figure S21. Plots of $K_{\mathrm{obs}}$ vs $\{2-\mathrm{Cs} 2\} / K_{\mathrm{obs}} . \mathrm{S} 18$

Figure S22. ${ }^{1} \mathrm{H}$ NMR spectra of 1 in $\mathrm{THF}-d 8(\mathrm{~A})$ and DMSO-d6 (B) at $25^{\circ} \mathrm{C} . \quad$ p. S19

Figure S23. ${ }^{1} \mathrm{H}$ NMR spectra of 2 in THF-d8 (A) and DMSO-d6 (B) at $25^{\circ}$ C. p. S20

Figure S24. $1 \mathrm{H}$ NMR spectra of 3 in THF- $d 8$ (A) and DMSO-d6 (B) at $25^{\circ} \mathrm{C} . \quad$ p. S21

Table S2. Equilibrium Constants of the enol/keto equilibrium for 1-3 in THF and DMSO. p. S21

Figure S25. Decoupled (A) and coupled (B) $13 \mathrm{C}$ NMR spectra of $\mathbf{3}$ in THF- $d 8$ at $25^{\circ} \mathrm{C} . \quad$ p. S23

Dienediolates SI v. $2.1 \quad$-S2- 


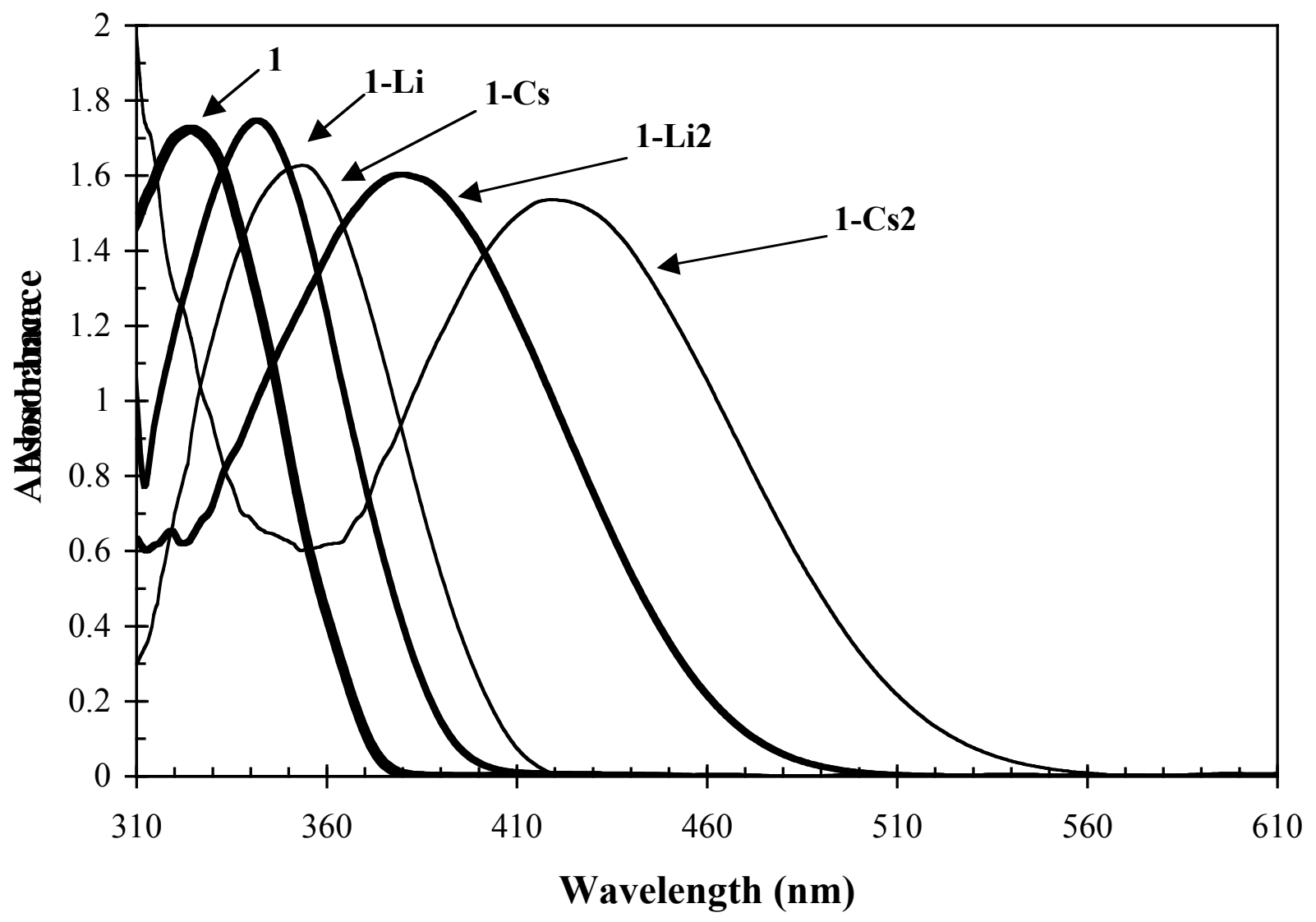

Figure S1. UV-vis Spectra of $\mathbf{1}$ and of the Corresponding Lithium and Cesium Mono- and Di- Enolates in THF. 


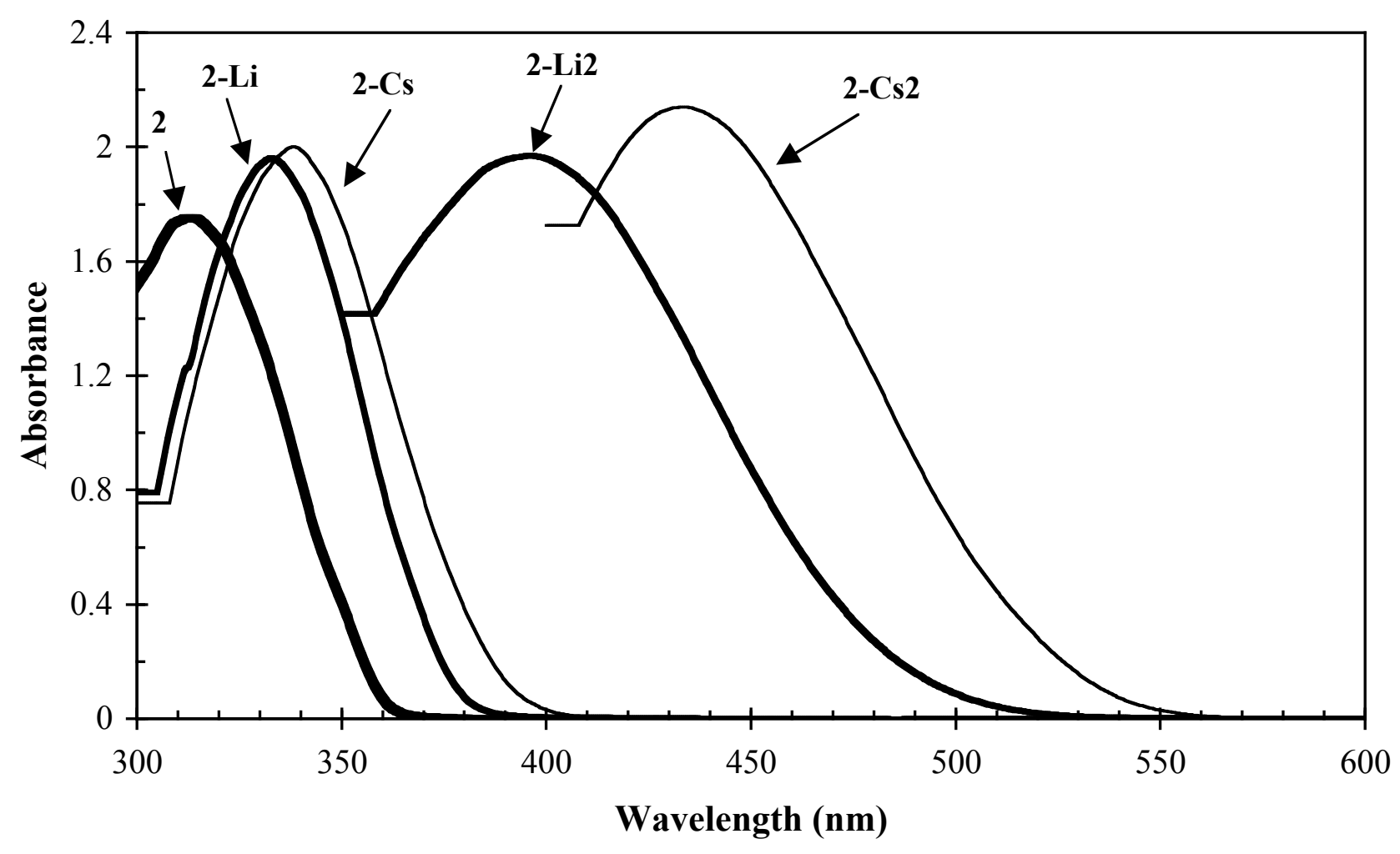

Figure S2. UV-vis spectra of $\mathbf{2}$ and its lithium and cesium mono- and di- enolates in THF. 


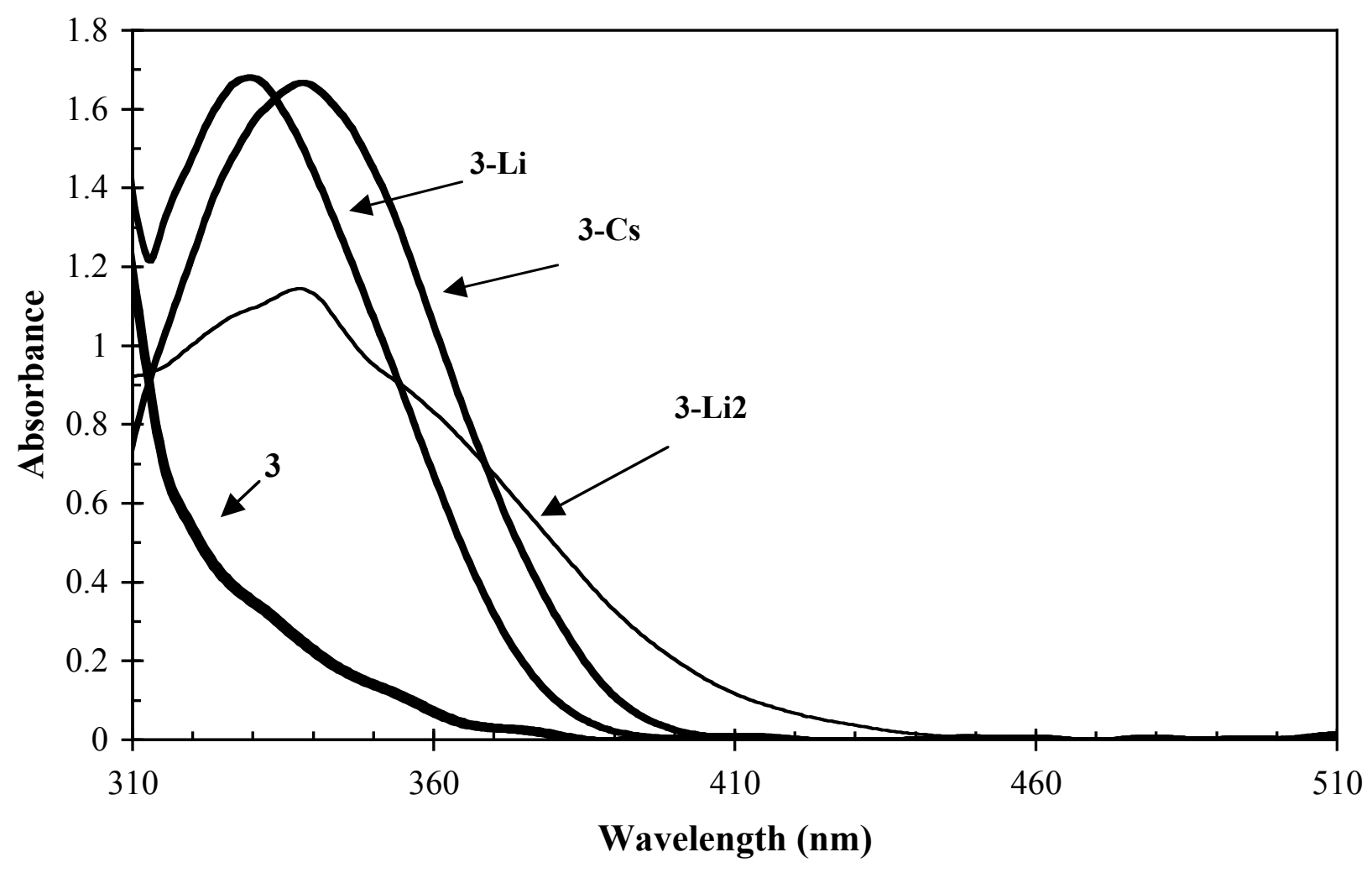

Figure S3. UV-vis spectra of $\mathbf{3}$ and its lithium and cesium mono- and di- enolates in THF. 


\section{Extinction Coefficient Experiments.}

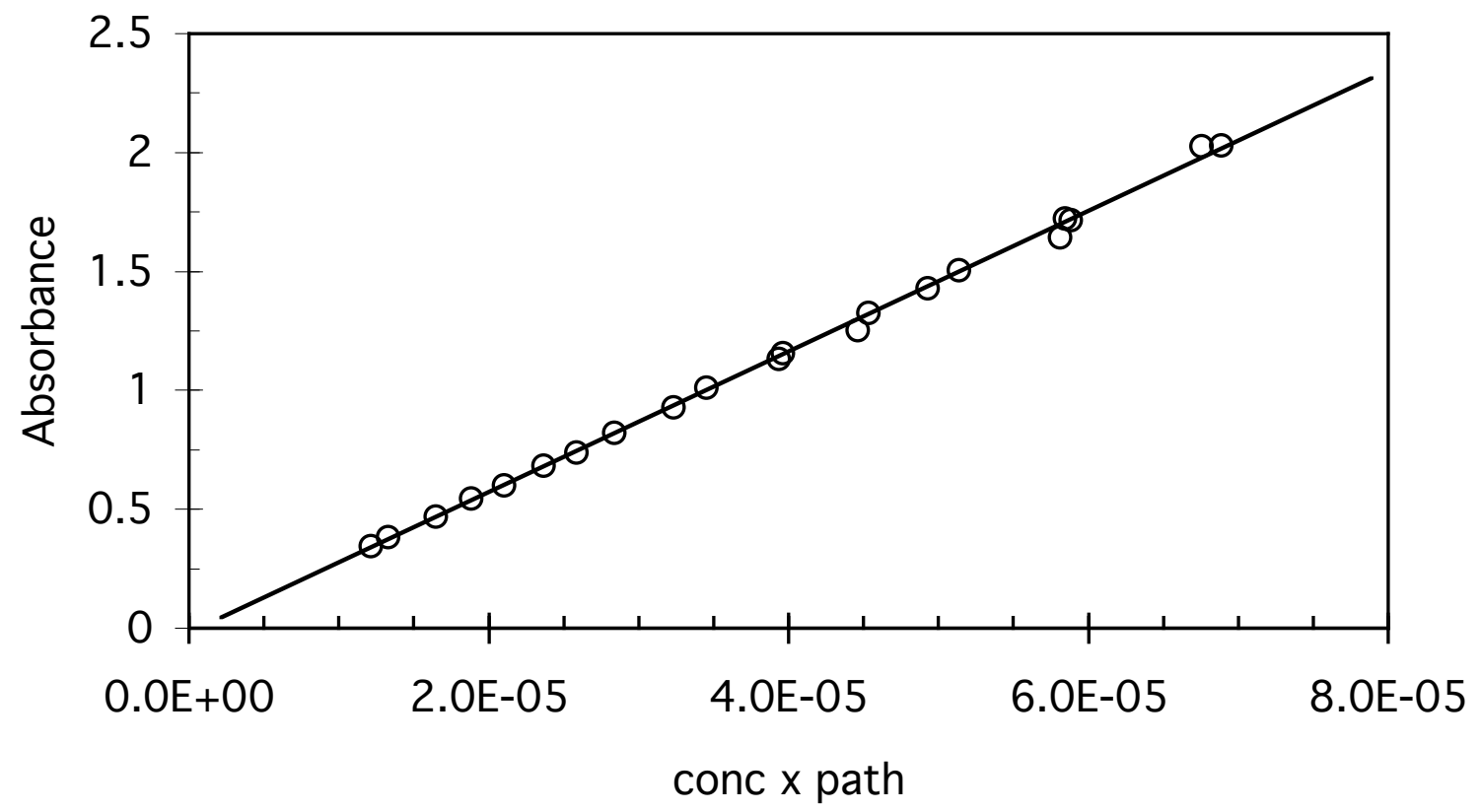

Figure S4. Absorbance of 1 for $1 \mathrm{~cm}$ pathlength at $324 \mathrm{~nm}$. The line shown is $(0.020 \pm 0.011)+(29580$ $\pm 264) \mathrm{x}$. The extinction coefficient is 29600 .

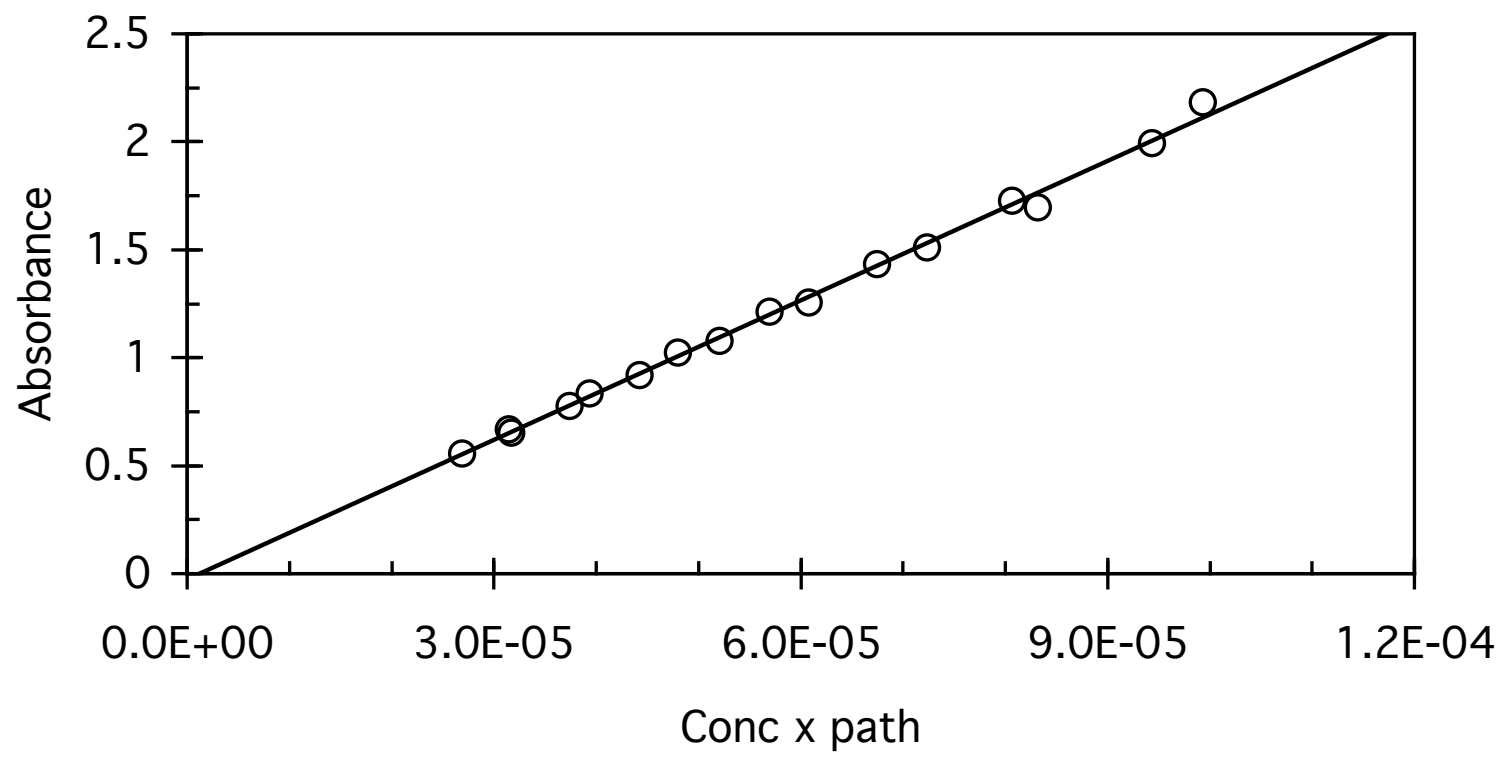

Figure S5. Absorbance of $1-\mathrm{Li}$ for $1 \mathrm{~cm}$ pathlength at $\lambda_{\max }(340-342 \mathrm{~nm})$. The line shown is $(0.027 \pm$ $0.021)+(21553 \pm 338) \mathrm{x}$. The extinction coefficient is 21550 . 


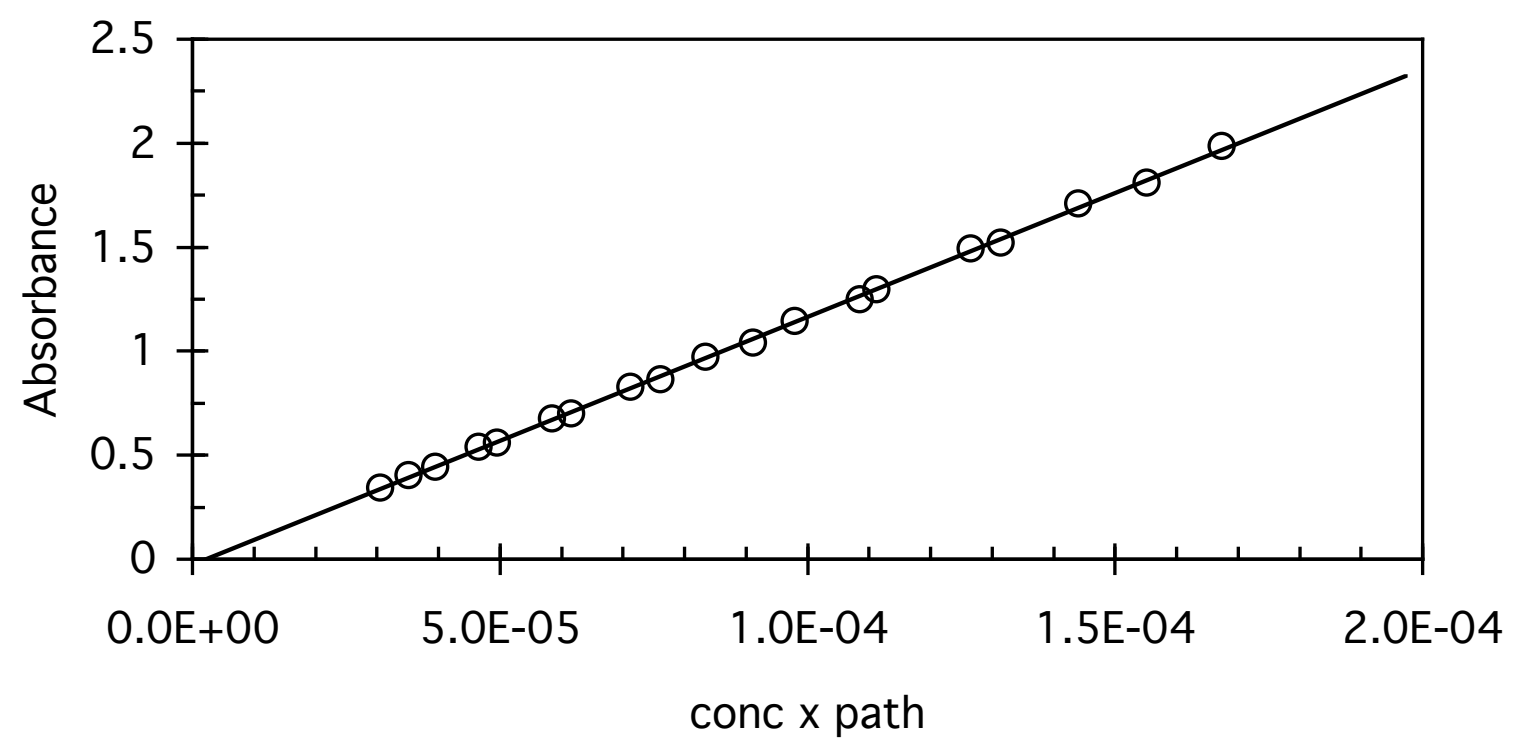

Figure S6. Absorbance of $\mathbf{1}-\mathrm{Li}_{2}$ for $1 \mathrm{~cm}$ pathlength at $\lambda_{\max }(379-381 \mathrm{~nm})$. The line shown is $(0.073 \pm$ $0.040)+(12952 \pm 393) \mathrm{x}$. The extinction coefficient is 12950 .

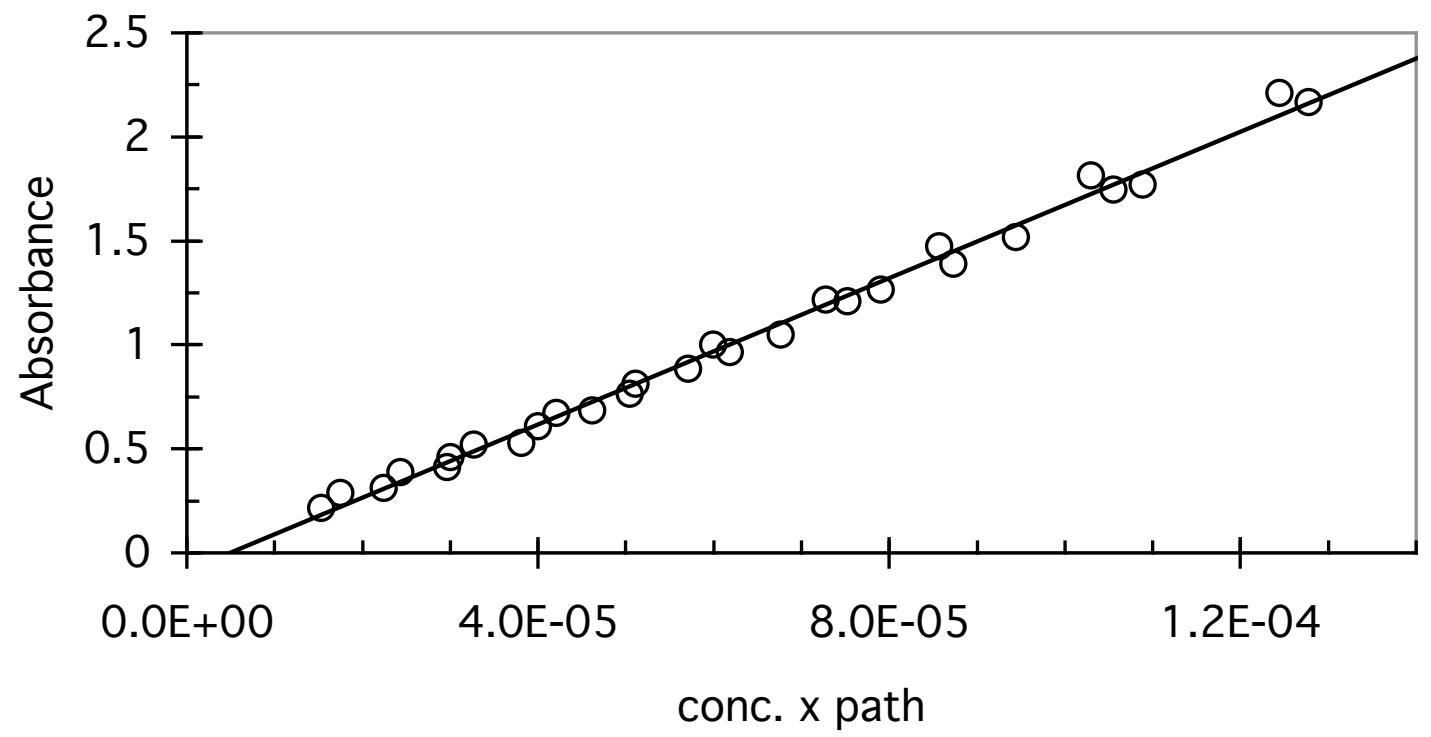

Figure S7. Absorbance of $1-C s$ for $1 \mathrm{~cm}$ pathlength at $\lambda_{\max }(418-421 \mathrm{~nm})$. The line shown is $(0.085 \pm$ $0.019)+(17569 \pm 278) \mathrm{x}$. The extinction coefficient is 17600 . 


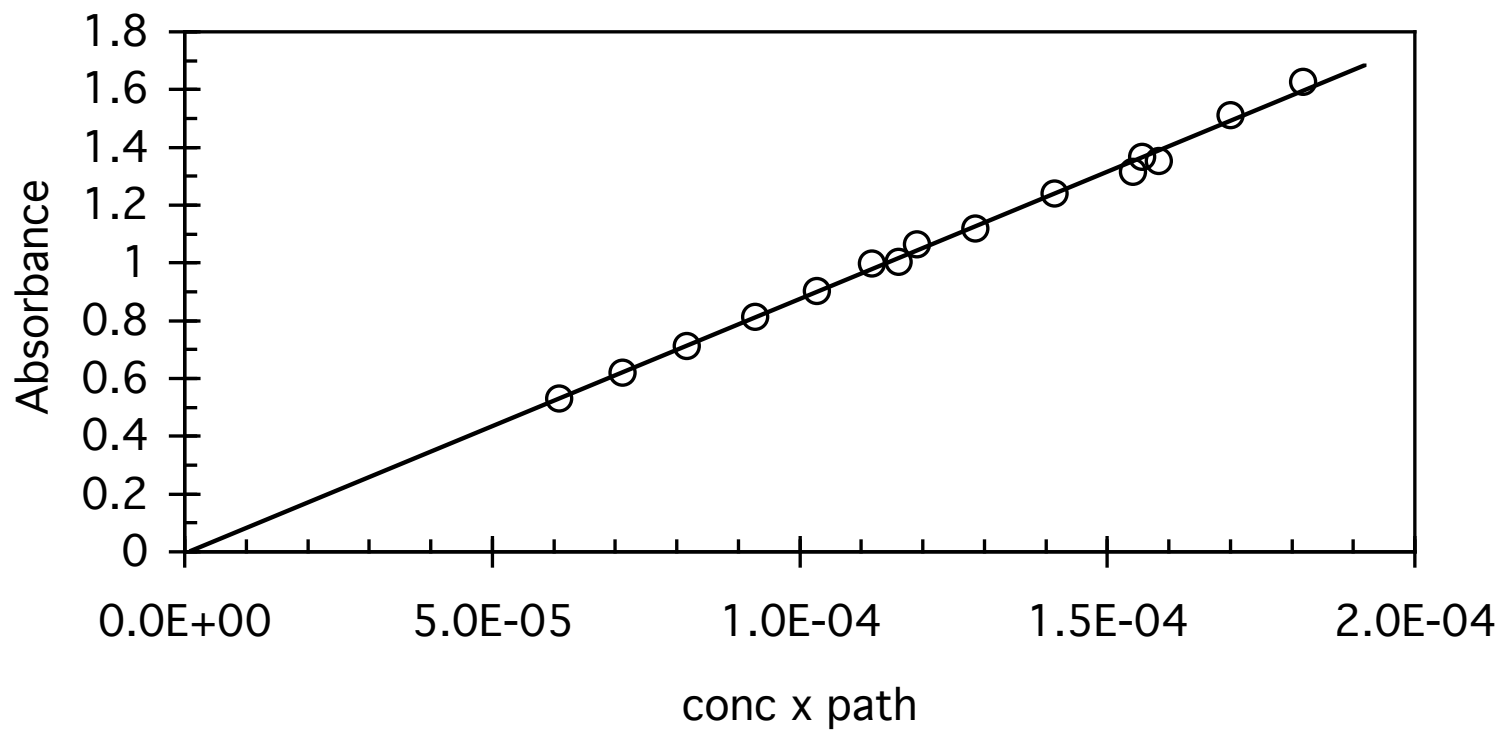

Figure S8. Absorbance of $1-\mathrm{Cs}_{2}$ for $1 \mathrm{~cm}$ pathlength at $\lambda_{\max }(418-421 \mathrm{~nm})$. The line shown is $(0.006 \pm$ $0.018)+(8816 \pm 141) \mathrm{x}$. The extinction coefficient is 8800 .

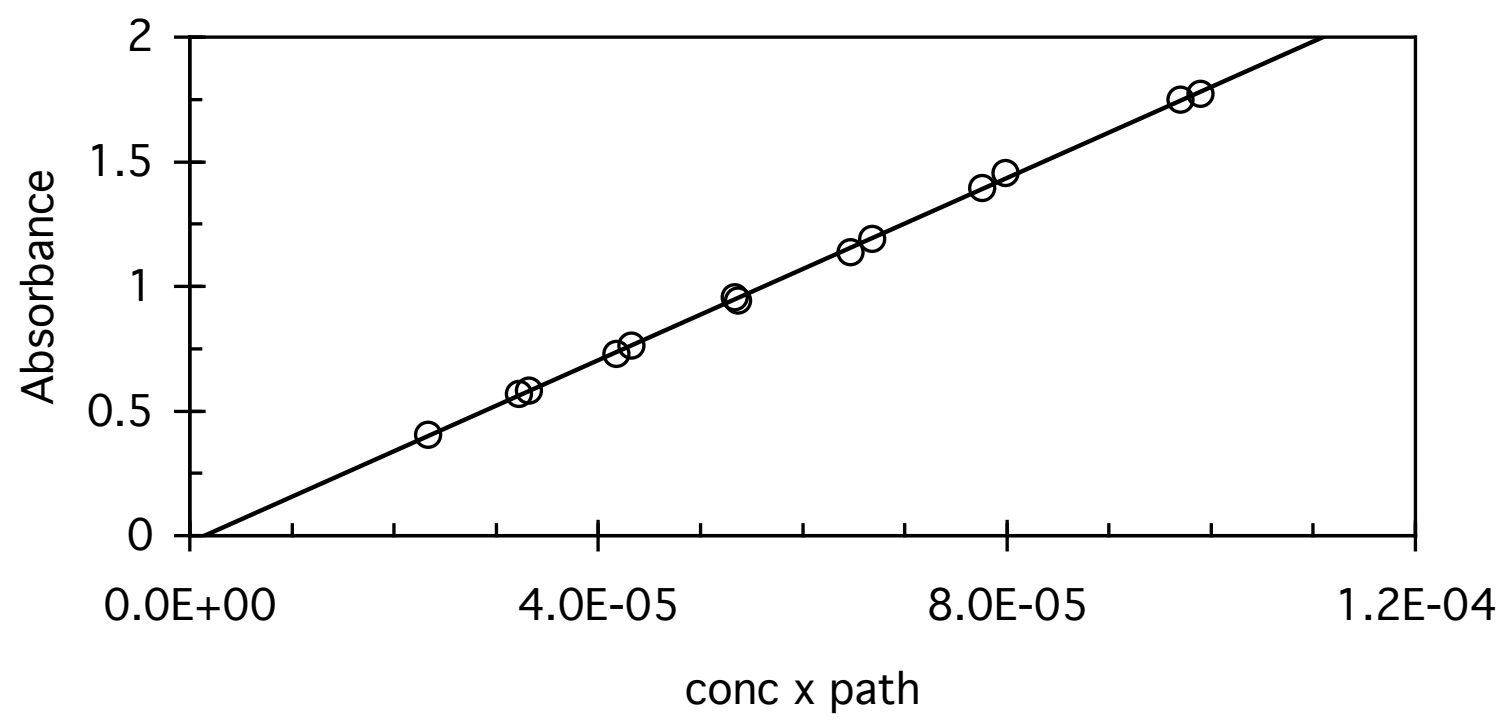

Figure S9. Absorbance of 2 for $1 \mathrm{~cm}$ pathlength at $312 \mathrm{~nm}$. The line shown is $(0.027 \pm 0.008)+(18265$ $\pm 123) \mathrm{x}$. The extinction coefficient is 18300 . 


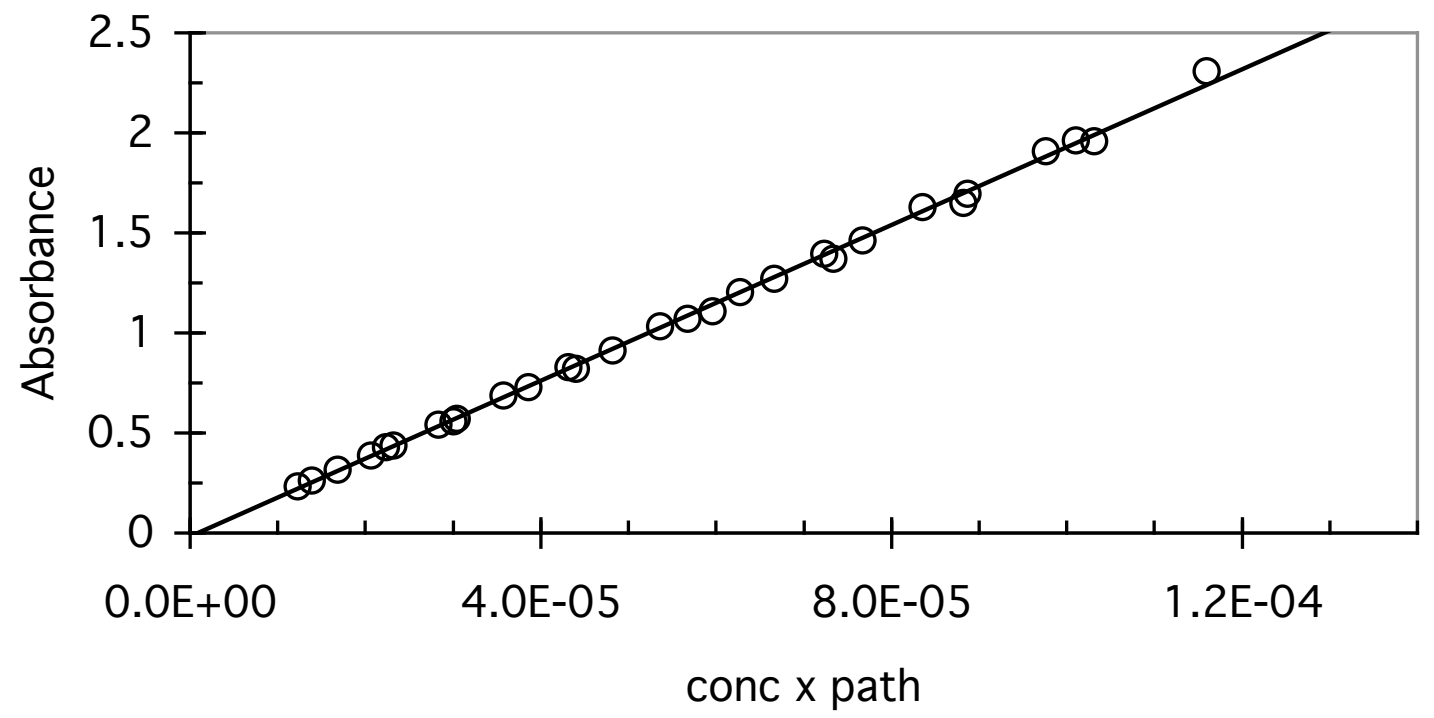

Figure S10. Absorbance of 2-Li for $1 \mathrm{~cm}$ pathlength at $\lambda_{\max }(333 \mathrm{~nm})$. The line shown is $(0.018 \pm$ $0.009)+(19457 \pm 146) \mathrm{x}$. The extinction coefficient is 19500 .

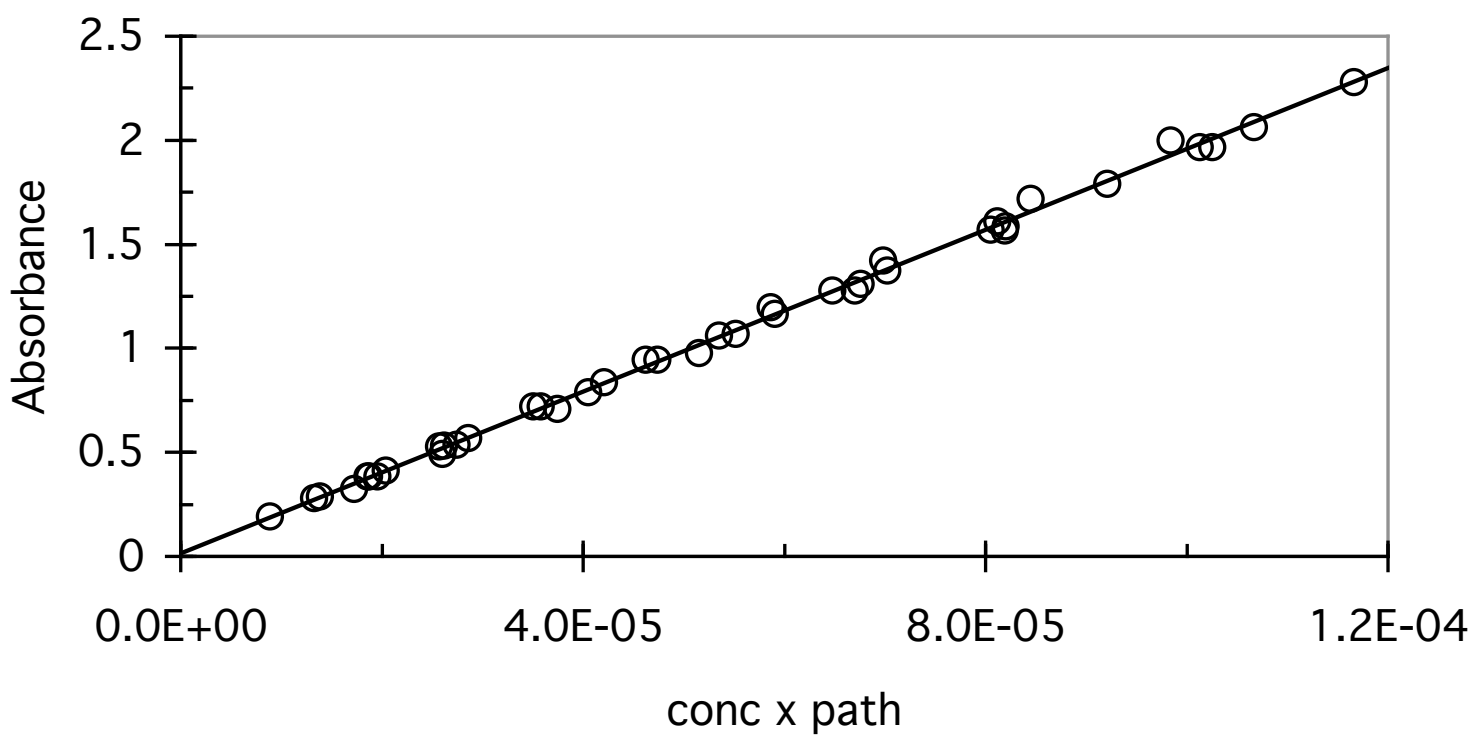

Figure S11. Absorbance of $2-\mathrm{Li}_{2}$ for $1 \mathrm{~cm}$ pathlength at $\lambda_{\max }(400-402 \mathrm{~nm})$. The line shown is $(0.015 \pm$ $0.009)+(19426 \pm 140) \mathrm{x}$. The extinction coefficient is 19400 . 


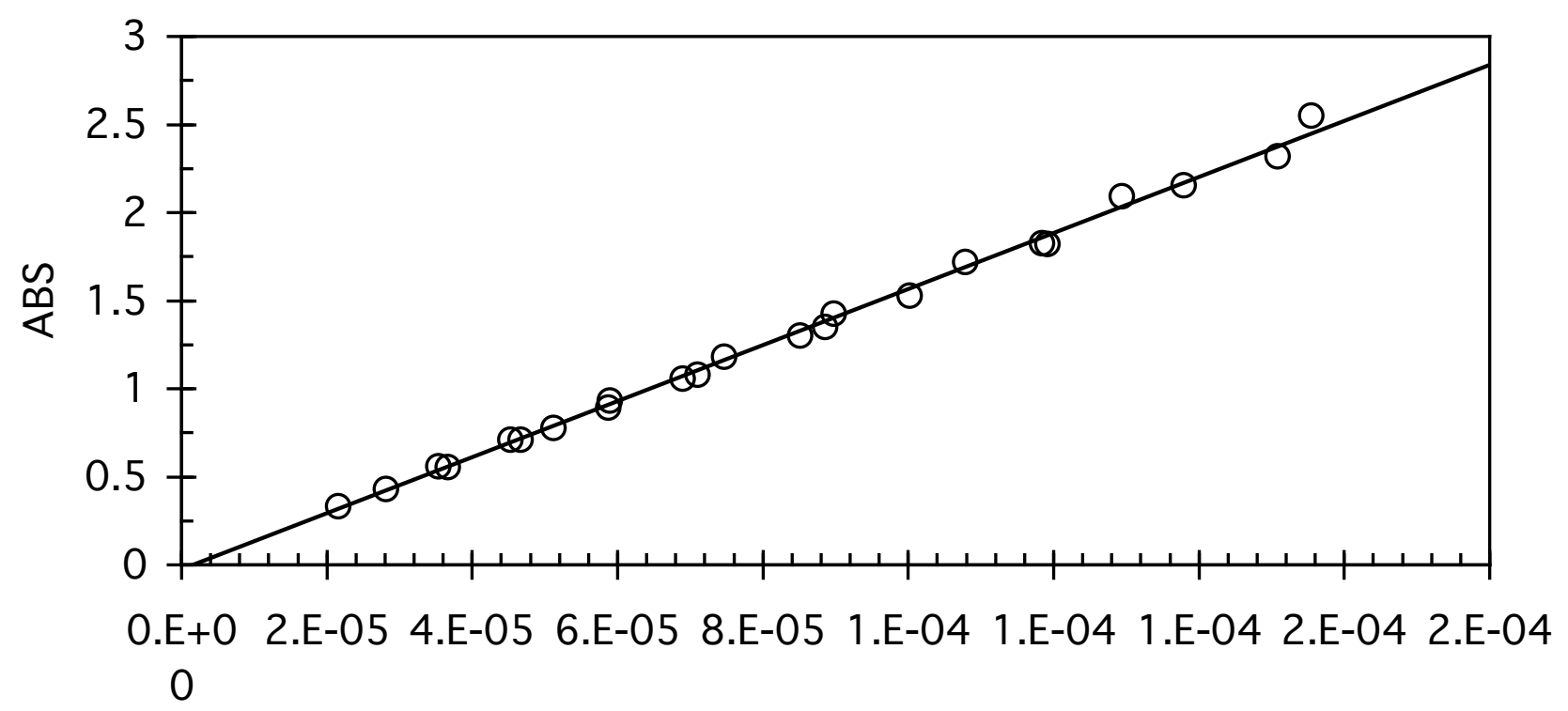

conc $x$ path

Figure S12. Absorbance of 2 -Cs for $1 \mathrm{~cm}$ pathlength at $\lambda_{\max }(338-340 \mathrm{~nm})$. The line shown is $(0.0255 \pm$ $0.018)+(15922 \pm 196) \mathrm{x}$. The extinction coefficient is 15900 .

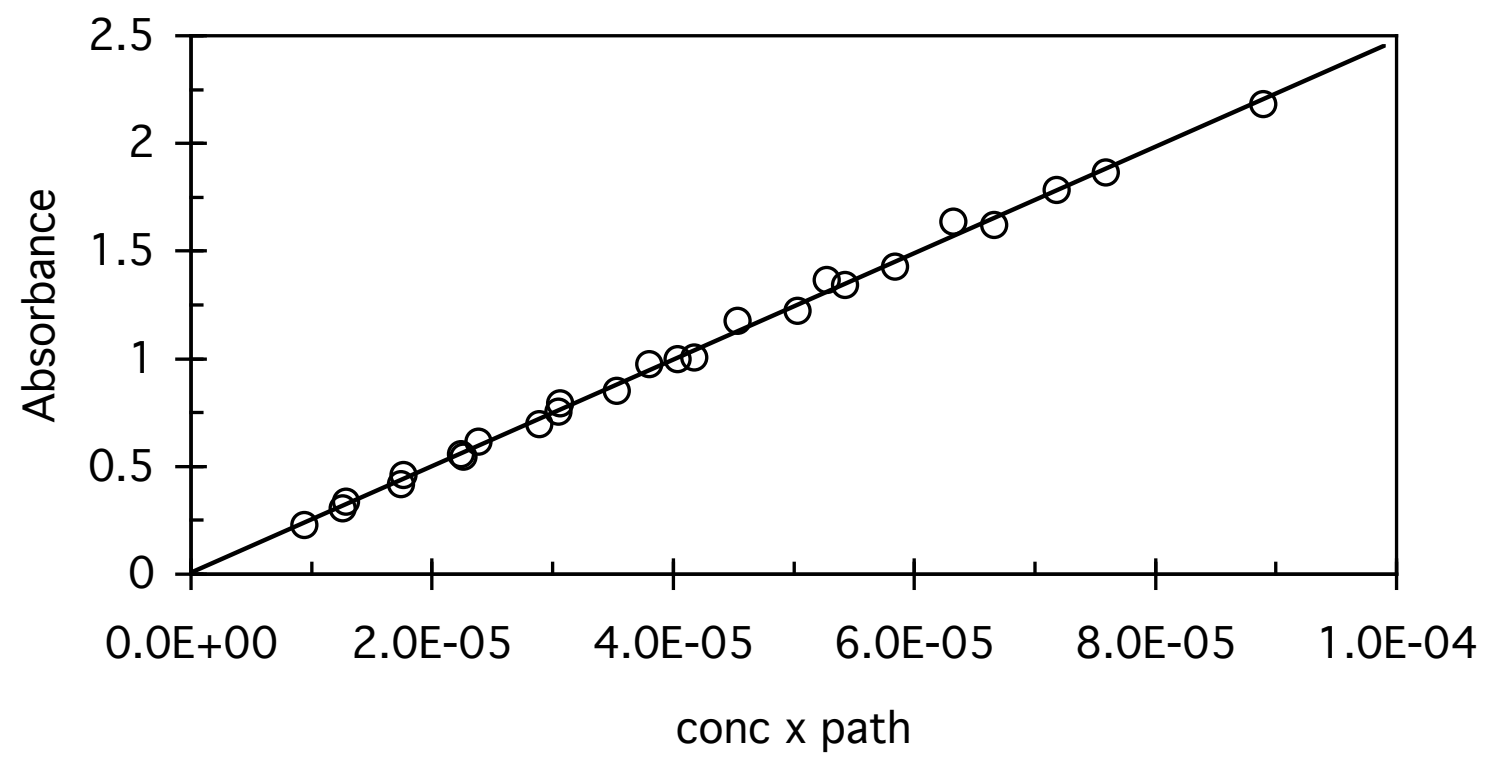

Figure S13. Absorbance of 2-Cs2 for $1 \mathrm{~cm}$ pathlength at $\lambda_{\max }(430-438 \mathrm{~nm})$. The line shown is $(0.007 \pm$ $0.012)+(24712 \pm 269) \mathrm{x}$. The extinction coefficient is 24700 . 


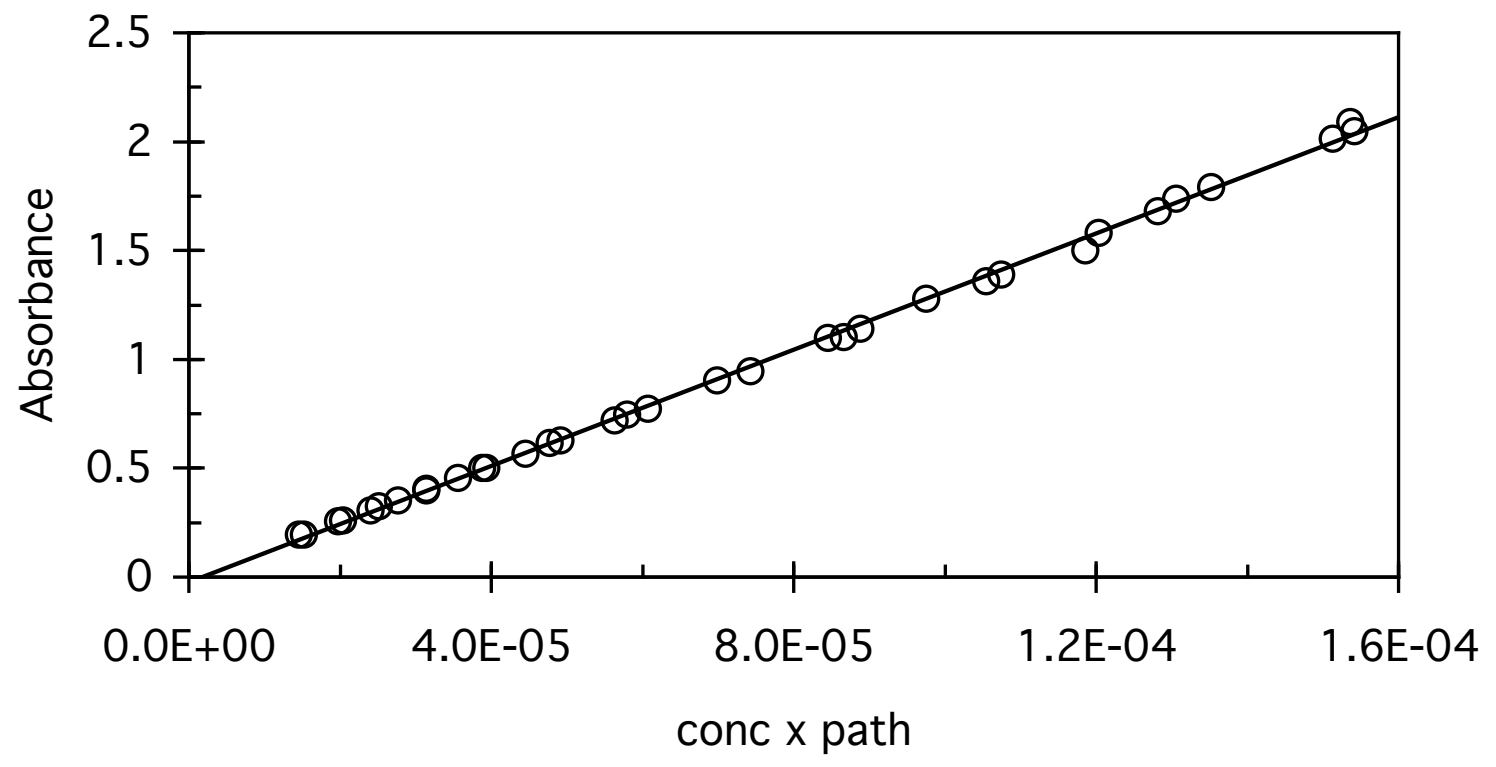

Figure S14. Absorbance of 3-Li for $1 \mathrm{~cm}$ pathlength at $\lambda_{\max }(329 \mathrm{~nm})$. The line shown is $(0.022 \pm$ $0.006)+(13328 \pm 80.5) \mathrm{x}$. The extinction coefficient is 13300 .

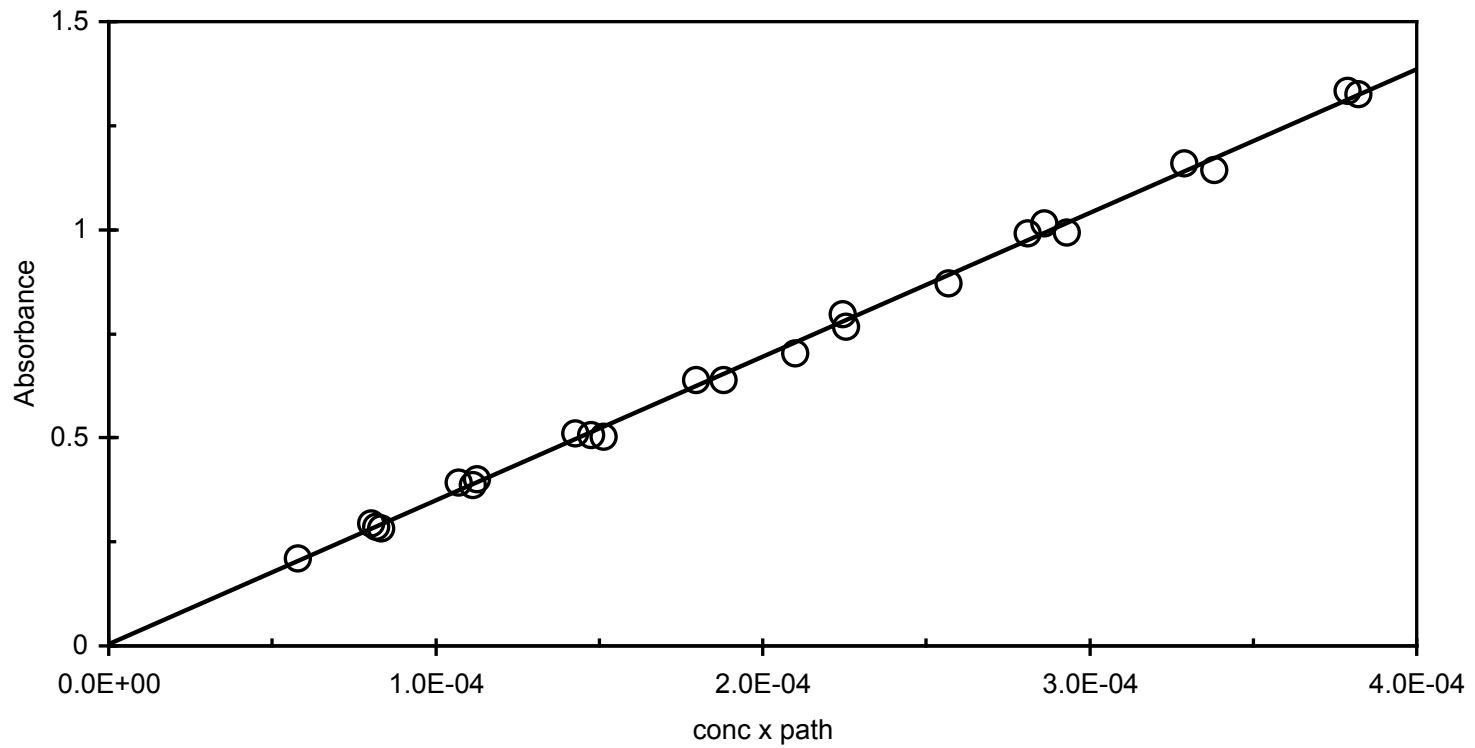

Figure S15. Absorbance of $3-\mathrm{Li}_{2}$ for $1 \mathrm{~cm}$ pathlength at $\lambda_{\max }(337 \mathrm{~nm})$. The line shown is $(0.004 \pm$ $0.008)+(3453 \pm 37) \mathrm{x}$. The extinction coefficient is 19400 . 


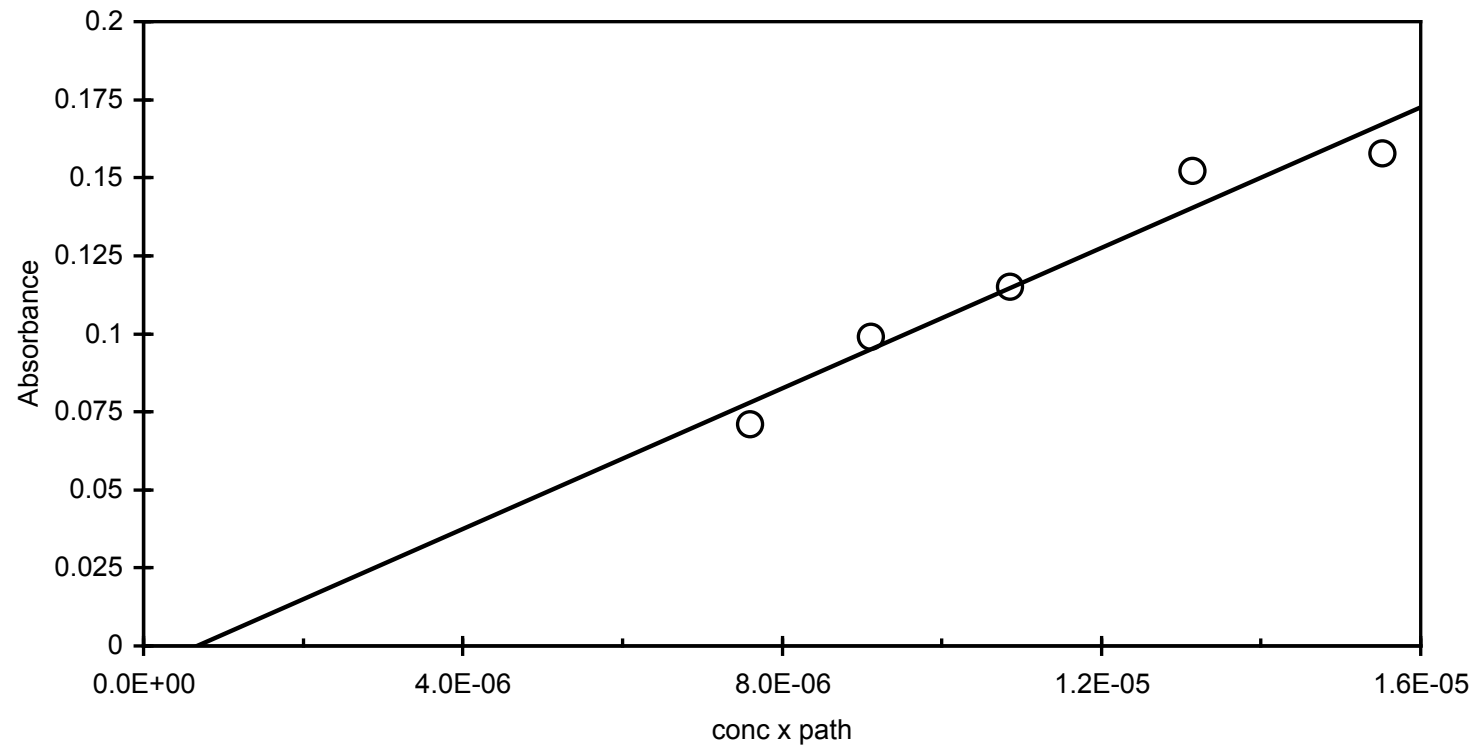

Figure S16. Absorbance of 3-Cs for $1 \mathrm{~cm}$ pathlength at $\lambda_{\max }(336 \mathrm{~nm})$. The line shown is $(0.007 \pm$ $0.018)+(11261 \pm 1562) \mathrm{x}$. The extinction coefficient is 11000 . 


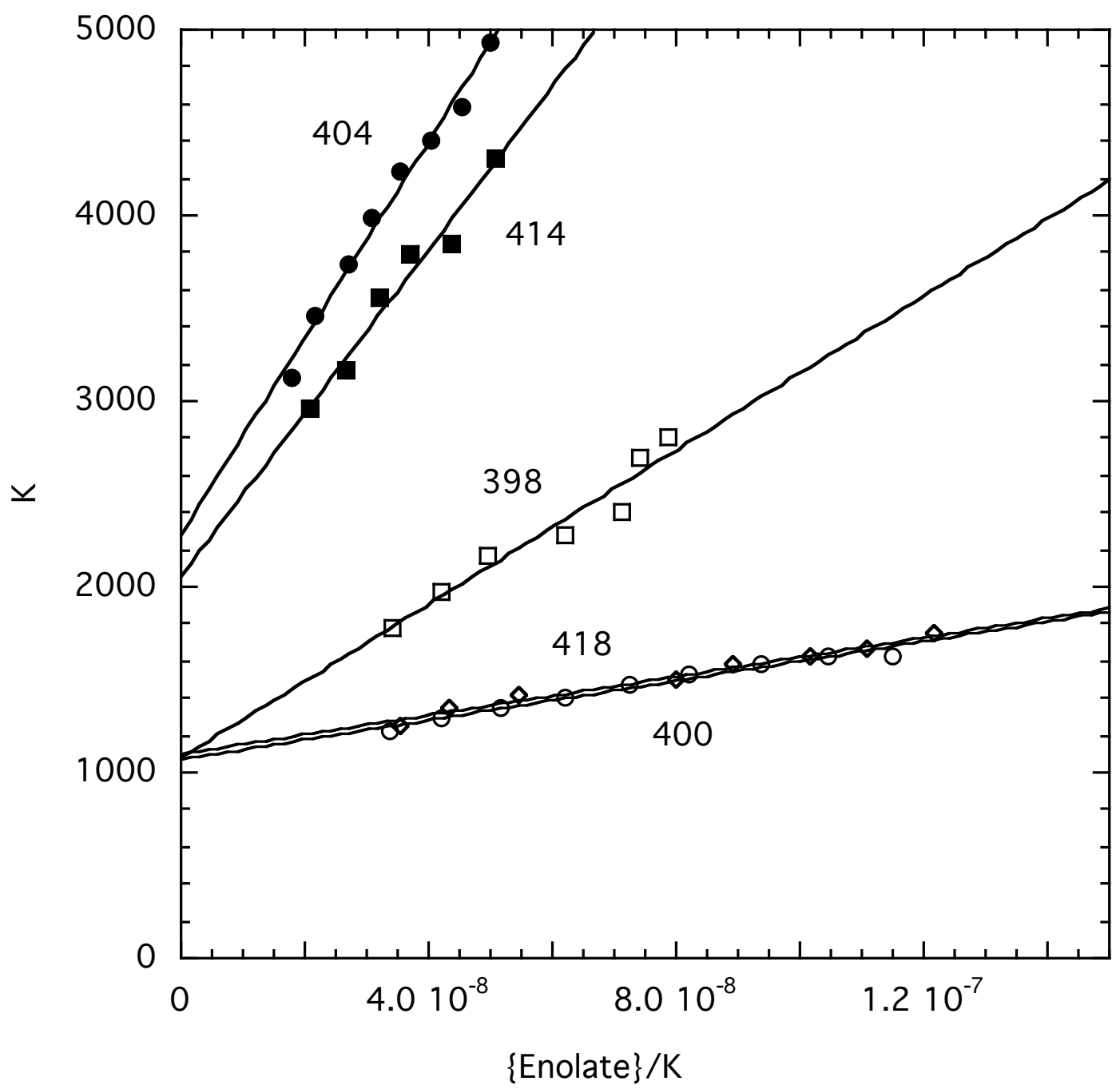

Fig S17. Plots of K(obs) vs \{Enolate\}/K(obs) for 1-Li (runs 398, 400 and 418) and 2-Li (runs 404 and 414). Properties of the regression lines are summarized in Table S1. 


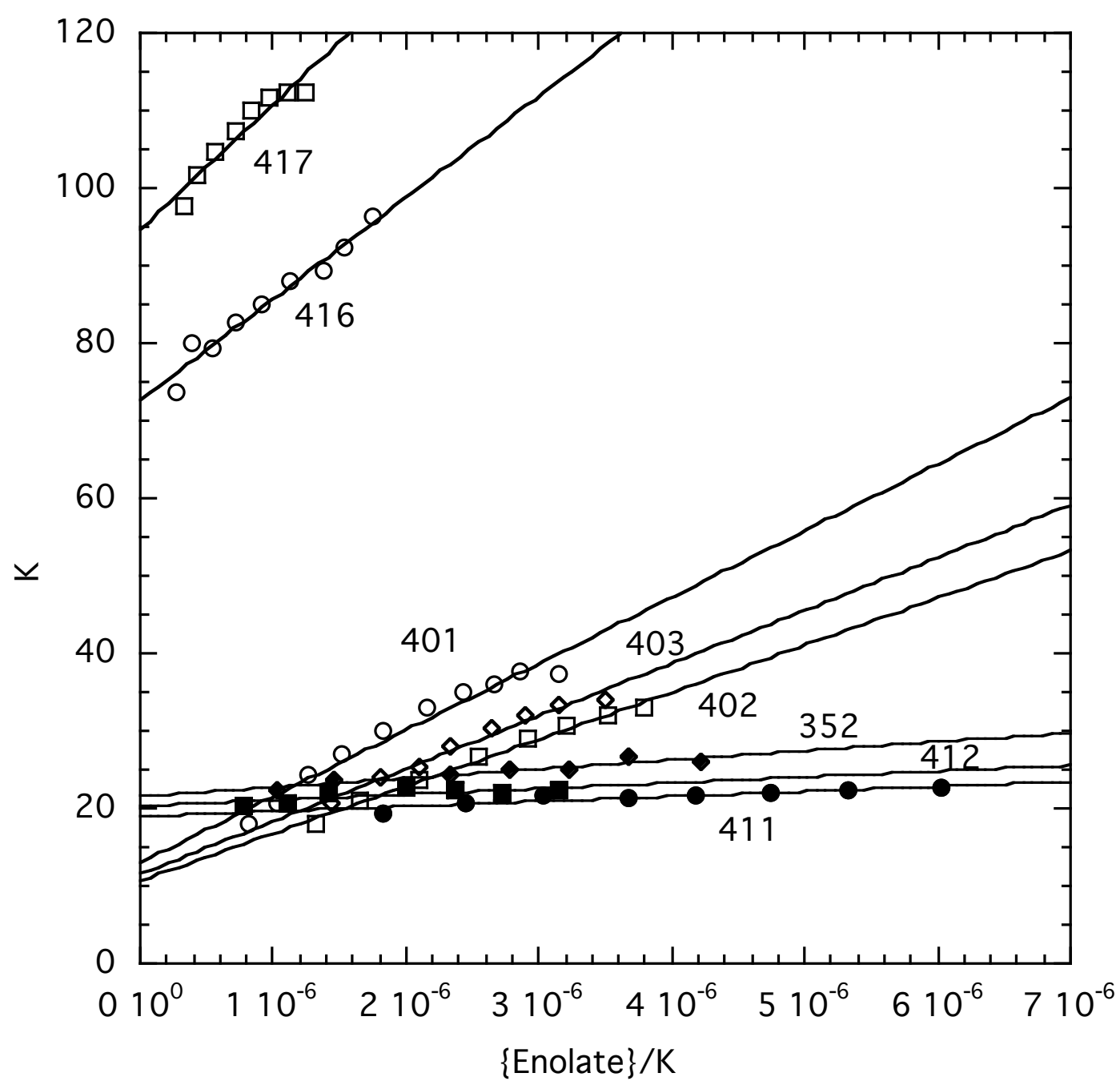

Figure S18. Plots of K(obs) vs \{Enolate\}/K(obs) for 3-Li (runs 401, 402 and 403), 1-Cs (runs 411, 412, 352) and 2-Cs (runs 416 and 417). Properties of the regression lines are summarized in Table S1.

Table S1. Properties of regression lines in Figure S17 and S18. The intercept is Ko; the slope $=2 \mathrm{~K}_{\mathrm{d}} \mathrm{Ko}^{2}$.

\begin{tabular}{|c|c|c|c|c|c|}
\hline Enolate & Run & \multicolumn{1}{c}{ Ko } & Slope & $\mathrm{R}^{2}$ & \multicolumn{1}{c|}{$\mathrm{Kd}$} \\
\hline $1-\mathrm{Li}$ & 398 & $1077 \pm 144$ & $(2.07 \pm 0.24) \mathrm{E} 10$ & 0.940 & $(8940 \pm 2600)$ \\
& 400 & $1070 \pm 25$ & $(5.30 \pm 0.33) \mathrm{E} 10$ & 0.974 & $2310 \pm 180$
\end{tabular}

Dienediolates SI v. 2.1 


\begin{tabular}{|llllll|} 
& 418 & $1100 \pm 27$ & $(5.22 \pm 0.32) \mathrm{E} 10$ & 0.978 & $2160 \pm 170$ \\
\hline 2-Li & 404 & $2284 \pm 91$ & $(5.29 \pm 0.26) \mathrm{E} 10$ & 0.986 & $5070 \pm 470$ \\
& 414 & $2098 \pm 143$ & $(4.39 \pm 0.39) \mathrm{E} 10$ & 0.969 & $5190 \pm 860$ \\
\hline $3-\mathrm{Li}$ & 401 & $12.97 \pm 1.41$ & $(8.57 \pm 0.67) \mathrm{E} 6$ & 0.954 & $25500 \pm 5900$ \\
& 402 & $10.70 \pm 0.69$ & $(6.07 \pm 0.25) \mathrm{E} 6$ & 0.990 & $26500 \pm 3600$ \\
& 403 & $11.92 \pm 1.07$ & $(6.80 \pm 0.42) \mathrm{E} 6$ & 0.978 & $25600 \pm 5000$ \\
\hline $1-\mathrm{Cs}$ & 411 & $18.99 \pm 0.49$ & $(6.43 \pm 0.12) \mathrm{E} 5$ & 0.832 & $890 \pm 170$ \\
& 412 & $20.33 \pm 0.60$ & $(7.47 \pm 0.29) \mathrm{E} 5$ & 0.576 & $900 \pm 350$ \\
& 352 & $21.59 \pm 0.55$ & $(11.66 \pm 1.93) \mathrm{E} 5$ & 0.880 & $1250 \pm 220$ \\
\hline $2-\mathrm{Cs}$ & 416 & $72.8 \pm 1.1$ & $(1.28 \pm 0.10) \mathrm{E} 7$ & 0.962 & $1210 \pm 100$ \\
& 417 & $94.7 \pm 1.8$ & $(1.61 \pm 0.21) \mathrm{E} 7$ & 0.907 & $900 \pm 120$ \\
\hline
\end{tabular}




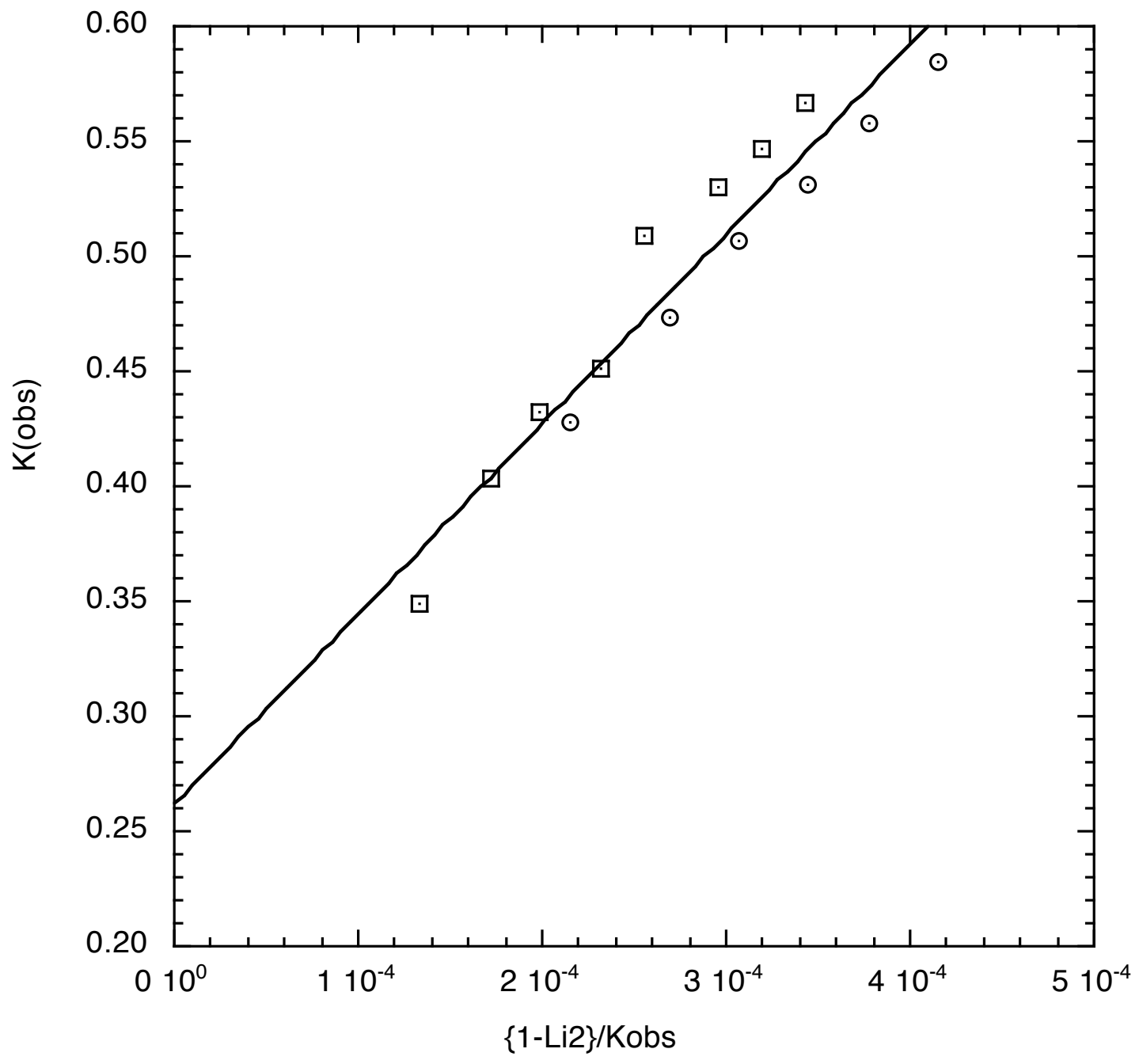

Figure S19. Plot of $K_{\mathrm{obs}}$ vs $\{\mathbf{1 - L i 2}\} / K_{\mathrm{obs}}$ for runs AF 241 and 242. The regression line shown is $0.262 \pm$ $0.019+(826 \pm 67) \mathrm{x}$. 


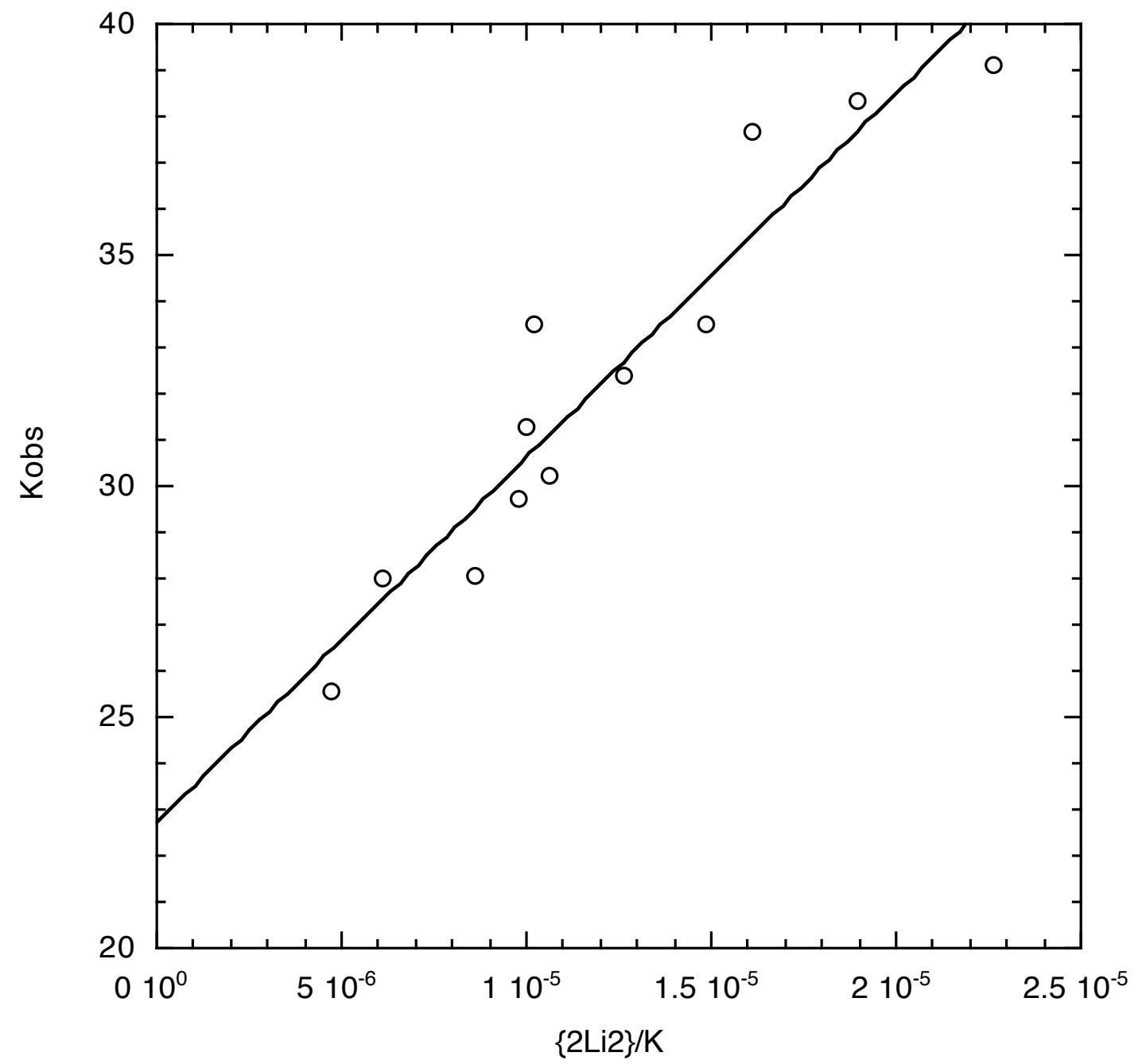

Figure S20. Plot of $K_{\mathrm{obs}}$ vs $\{\mathbf{2}-\mathbf{L i 2}\} / K_{\mathrm{obs}}$ for runs AF 309 and 317. The regression line shown is $22.73 \pm$ $1.10+(7.89 \pm 0.84) \mathrm{E} 5 \mathrm{x} ; \mathrm{R}^{2}=0.928$. 


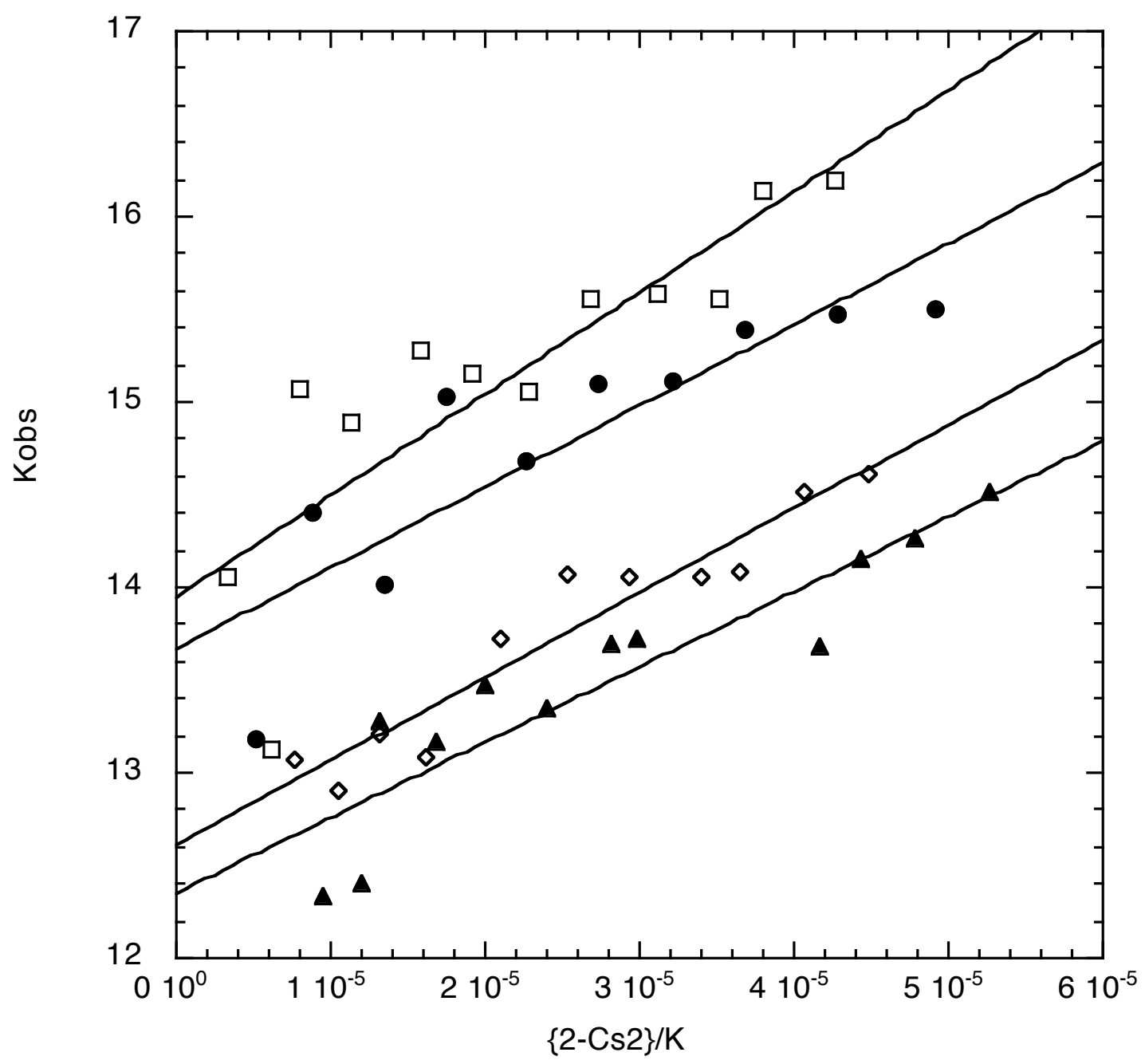

Figure S21. Plots of $K_{\mathrm{obs}}$ vs $\{$ 2-Cs2 $\} / K_{\mathrm{obs}}$. Regression lines shown are: Run AF 313, filled circles: 13.67 $\pm 0.26+(43700 \pm 8800) x$. Run AF 355, open squares: $13.95 \pm 0.28+(54600 \pm 11000) x$. Run 365 , open diamonds: $12.61 \pm 0.13+(45400 \pm 4500) x$. Run AF 366, filled triangles: $12.35 \pm 0.18+(40600 \pm$ $5700) x$. Derived values of $K_{\mathrm{D}, 2}$ are $143,140,142,133$, respectively. 


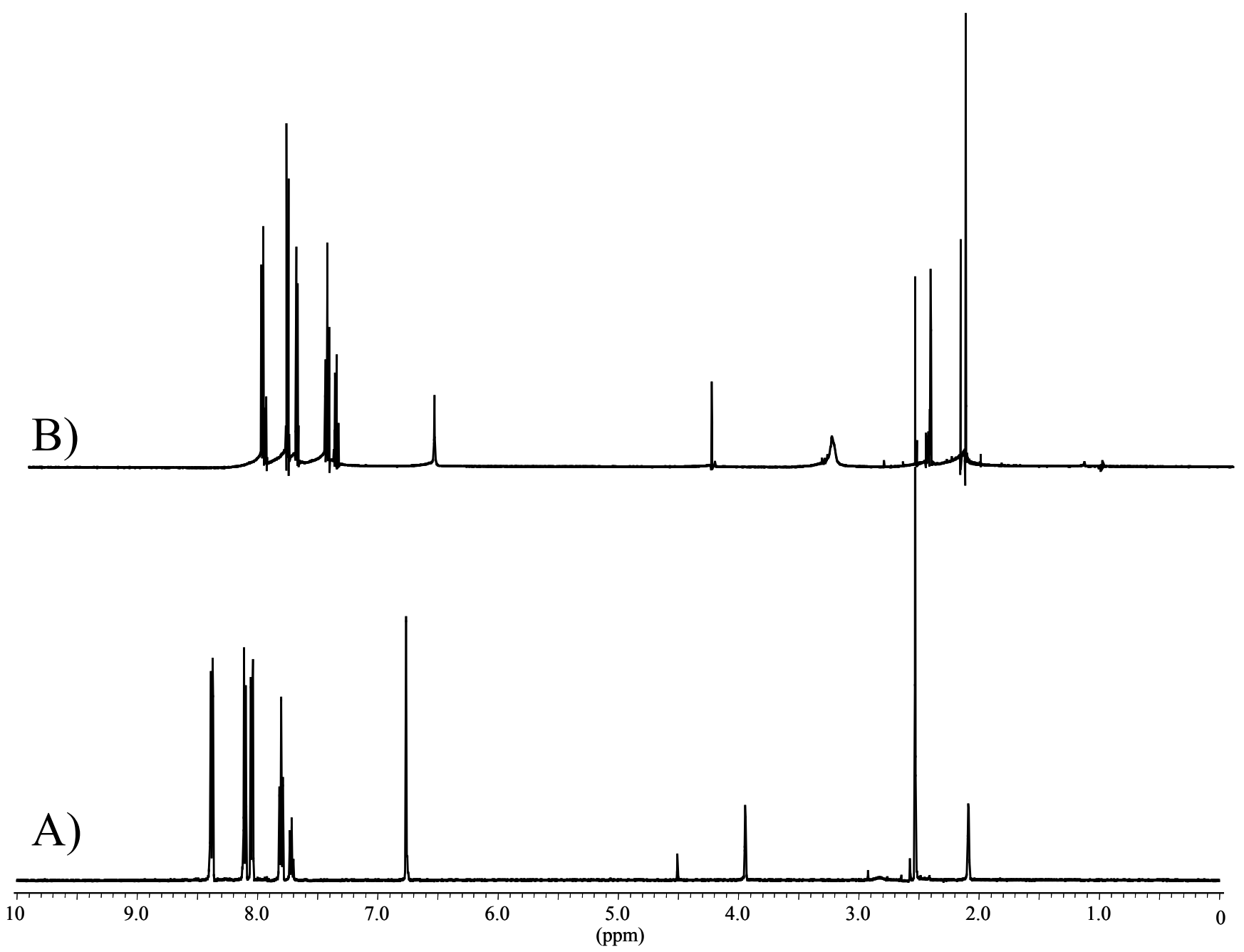

Figure S22. ${ }^{1} \mathrm{H}$ NMR spectra of 1 in THF-d8 (A) and DMSO-d6 (B) at $25^{\circ} \mathrm{C}$. 


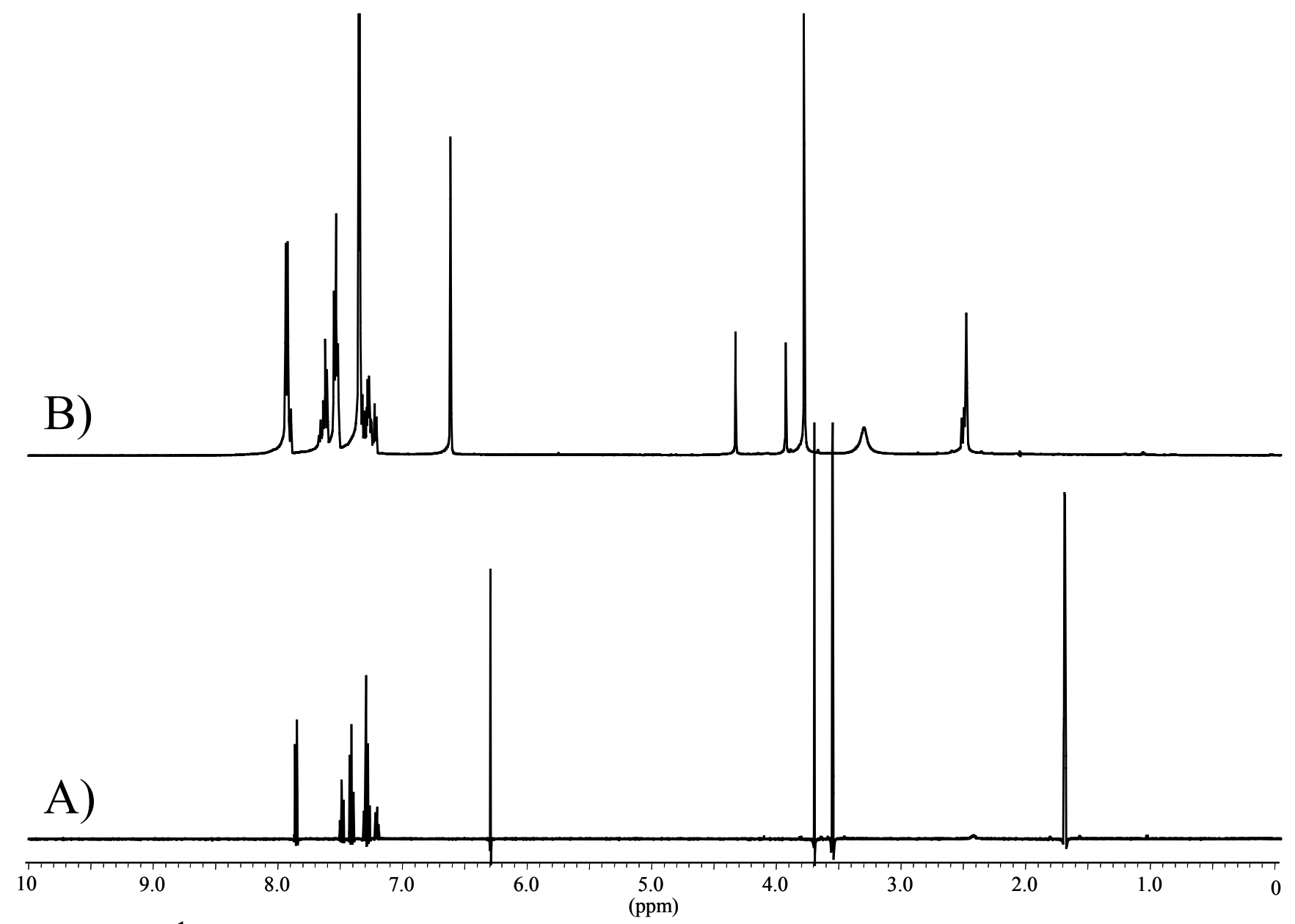

Figure S23. ${ }^{1} \mathrm{H}$ NMR spectra of 2 in THF- $d 8$ (A) and DMSO-d6 (B) at $25^{\circ} \mathrm{C}$. 


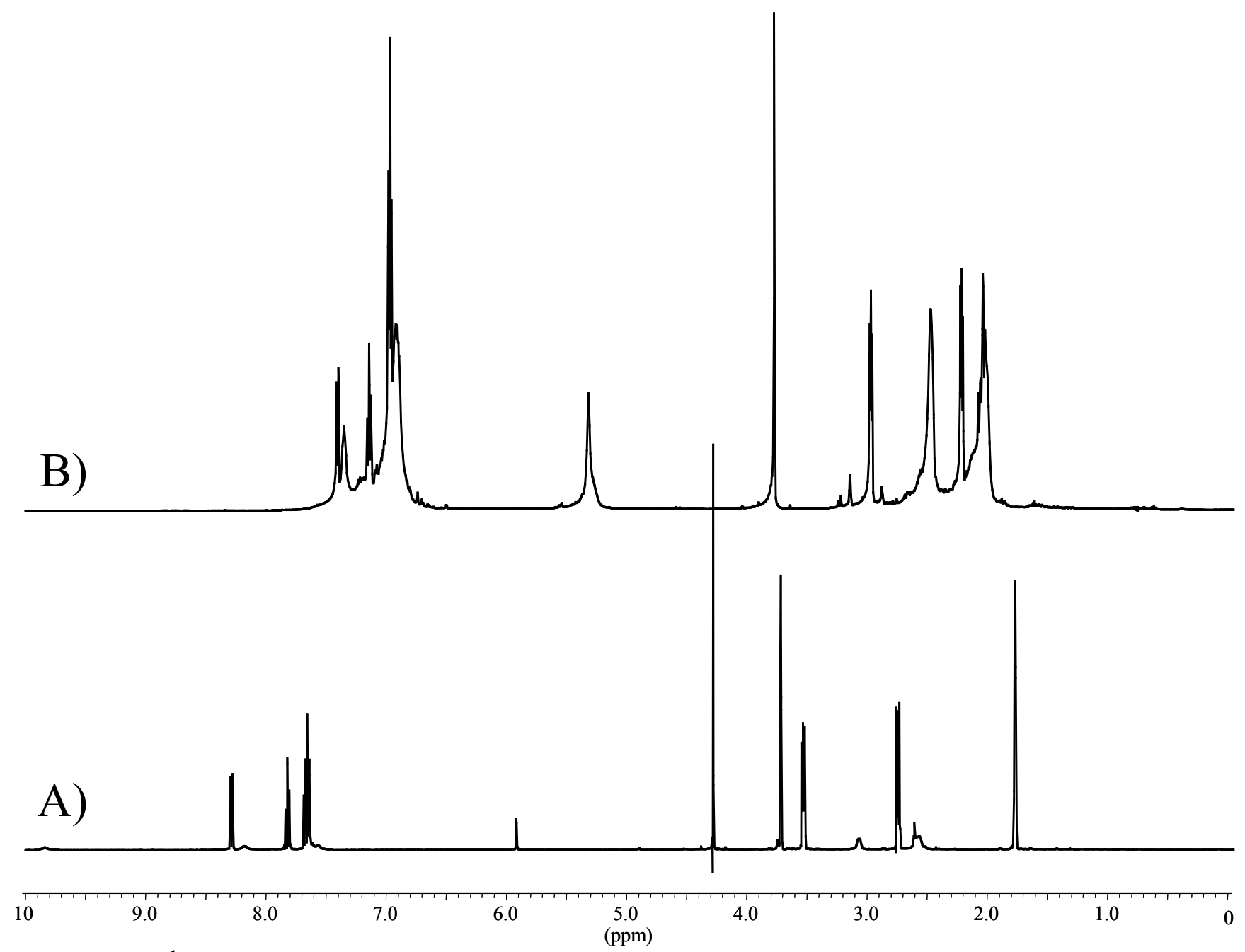

Figure S24. ${ }^{1} \mathrm{H}$ NMR spectra of 3 in THF- $d 8$ (A) and DMSO- $d 6$ (B) at $25^{\circ} \mathrm{C}$.

Table S2. Equilibrium Constants of the enol/keto equilibrium for 1-3 in THF and DMSO.

\begin{tabular}{|c|c|c|c|c|c|c|c|c|}
\hline Compound & Solvent & Experiment & $\begin{array}{c}\text { Enol-form } \\
\text { Integral }\end{array}$ & $\begin{array}{c}\text { Keto-form } \\
\text { Integral }\end{array}$ & $\begin{array}{c}\text { Total } \\
\text { Integral }\end{array}$ & $\begin{array}{c}\text { Enol-form } \\
\%\end{array}$ & $\begin{array}{c}\text { Keto-form } \\
\%\end{array}$ & Keq \\
\hline \multirow[t]{5}{*}{1} & THF & 1 & 1.00 & 0.08 & 1.08 & 92.4 & 7.6 & 12.1 \\
\hline & & 2 & 1.00 & 0.08 & 1.08 & 92.8 & 7.1 & 13.0 \\
\hline & & 3 & 1.00 & 0.10 & 1.10 & 91.2 & 8.8 & 10.4 \\
\hline & & & & & Average & 92.2 & 7.8 & 11.7 \\
\hline & & & & & St. Dev. & 0.9 & 0.9 & 1.4 \\
\hline 1 & DMSO & 1 & 0.95 & 0.22 & 1.17 & 81.0 & 19.0 & 4.3 \\
\hline Dienediolat & SI v. 2 & & & & & & & \\
\hline
\end{tabular}




\begin{tabular}{|c|c|c|c|c|c|c|c|c|}
\hline & & 2 & 1.00 & 0.27 & 1.27 & 78.4 & 21.6 & 3.6 \\
\hline & & 3 & 1.00 & 0.29 & 1.29 & 77.8 & 22.2 & 3.5 \\
\hline & & & & & Average & 79.1 & 20.9 & 3.8 \\
\hline & & & & & St. Dev. & 1.7 & 1.7 & 0.4 \\
\hline 2 & THF & 1 & 1.00 & 0.01 & 1.01 & 99.1 & 0.9 & 115 \\
\hline & & 2 & 1.05 & 0.01 & 1.06 & 99.1 & 0.9 & 106 \\
\hline & & 3 & 1.00 & 0.01 & 1.01 & 99.2 & 0.8 & 120 \\
\hline & & & & & Average & 99.1 & 0.9 & 113 \\
\hline & & & & & St. Dev. & 0.1 & 0.1 & 7 \\
\hline 2 & DMSO & 1 & 0.90 & 0.34 & 1.24 & 72.3 & 27.7 & 2.6 \\
\hline & & 2 & 1.00 & 0.43 & 1.43 & 70.1 & 29.9 & 2.3 \\
\hline & & 3 & 1.00 & 0.42 & 1.42 & 70.5 & 29.5 & 2.4 \\
\hline & & & & & Average & 71.0 & 29.0 & 2.4 \\
\hline & & & & & St. Dev. & 1.2 & 1.2 & 0.1 \\
\hline 3 & THF & 1 & 1.21 & 14.57 & 15.78 & 7.7 & 92.3 & 0.08 \\
\hline & & 2 & 1.00 & 12.42 & 13.42 & 7.5 & 92.5 & 0.08 \\
\hline & & 3 & 1.00 & 11.73 & 12.73 & 7.9 & 92.1 & 0.09 \\
\hline & & & & & Average & 7.7 & 92.3 & 0.08 \\
\hline & & & & & St. Dev. & 0.2 & 0.2 & 0.00 \\
\hline 3 & DMSO & 1 & 0.94 & 0.93 & 1.87 & 50.4 & 49.6 & 1.02 \\
\hline & & 2 & 1.00 & 0.92 & 1.92 & 52.1 & 47.9 & 1.09 \\
\hline & & 3 & 1.00 & 0.89 & 1.89 & 53.0 & 47.0 & 1.13 \\
\hline & & & & & Average & 51.8 & 48.3 & 1.08 \\
\hline
\end{tabular}

Dienediolates SI v. 2.1 


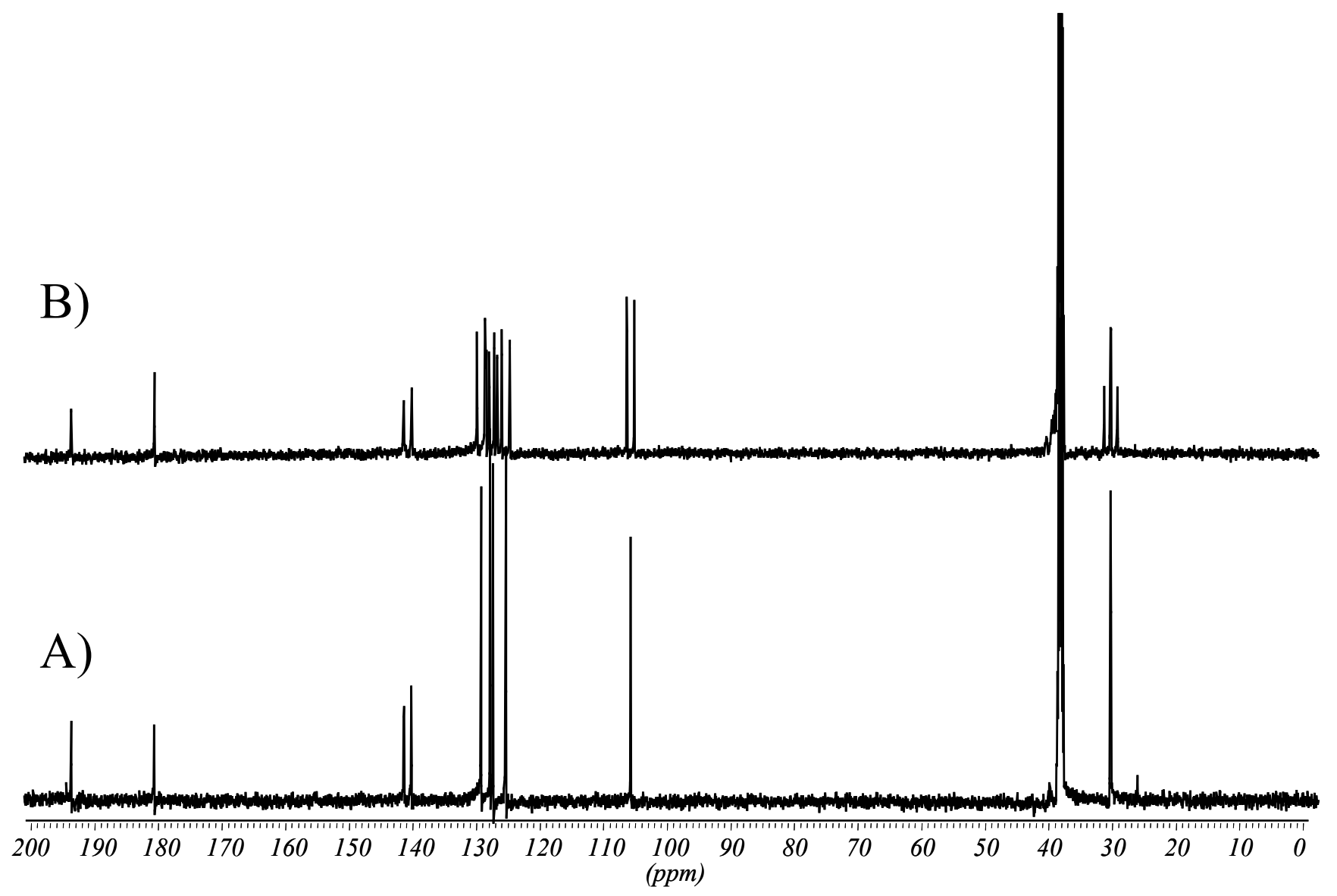

Figure S25. Decoupled (A) and coupled (B) $13 \mathrm{C} \mathrm{NMR} \mathrm{spectra} \mathrm{of} 3$ in THF- $d 8$ at $25^{\circ} \mathrm{C}$. 
Dienediolates SI v. 2.1

-S25- 